\title{
BARBARA GRAF, RESIDENCY JULY-AUGUST 2019
}

\author{
Michele Beevors
}

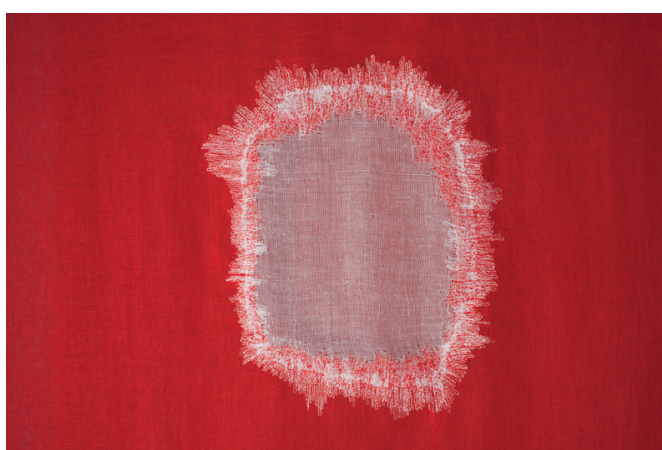

Figure I.

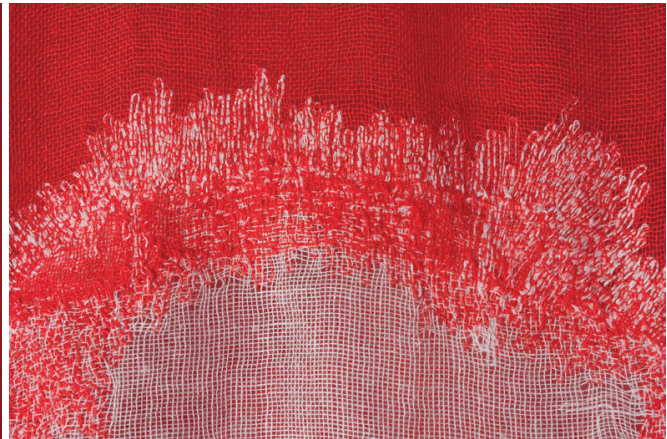

Figure 2.

Barbara Graf seems to have started her working life as an artist from an intersection with modernism, especially the figurative traditions of Leger and Gabo, and from the spaces that modernity had left behind: anatomy and the human form. While these ideas have always been of interest to her, her engagement with textiles, photography and film seem to have been influenced by travel and by the figurative traditions of Leonardo's drawings.

During her residency at Dunedin School of Art in June 2019, Graf held a day-long workshop for sculpture and textile students on experimental embroidery, a public seminar and an exhibition, "Volatile Bodies," a survey of her practice in the School of Art Gallery. "Volatile Bodies" included many of Graf's earlier works concerned with the idea of the concertinaed body; assembled anatomical studies of a pop-out human form; five video monitors showing animations; photographs; and elaborations on experimental embroidery, works with cloth that hung in the gallery space. The cloth works were arranged so that the viewer could see around and though them to other works. Photographs of the artist performing for the camera behind, underneath and veiled by fabric were arranged between other works. The gallery space was filled with works, some of which were elaborately detailed, while others were iterations and stepping stones pointing in different directions. Viewers might have had a sense of a career of singular intent, of conceptual somersaulting and highly skilled labour as they moved around the exhibition.

"Volatile Bodies" painted a trajectory whereby the more outward-looking, modernist works - for the early works, think Hans Bellmer or Nancy Graves - had led to personal explorations, self-motivated by intimate knowledge of the sensuous body and the materials used. Shrouded in secrecy and personal subjectivity, the human body (its skin) is laid bare for the invasive gaze of medicine, which turns the idea of the intimate and personal into a shared experience - as anyone who has been under the knife, screened for cancer, jabbed by a needle or prodded and poked by modern medicine can attest to. It is the development of the work towards the exposed yet veiled experience of describing, of understanding the body, the sensations and sensuality, pain and abjection, that Graf's work evokes for this viewer. 


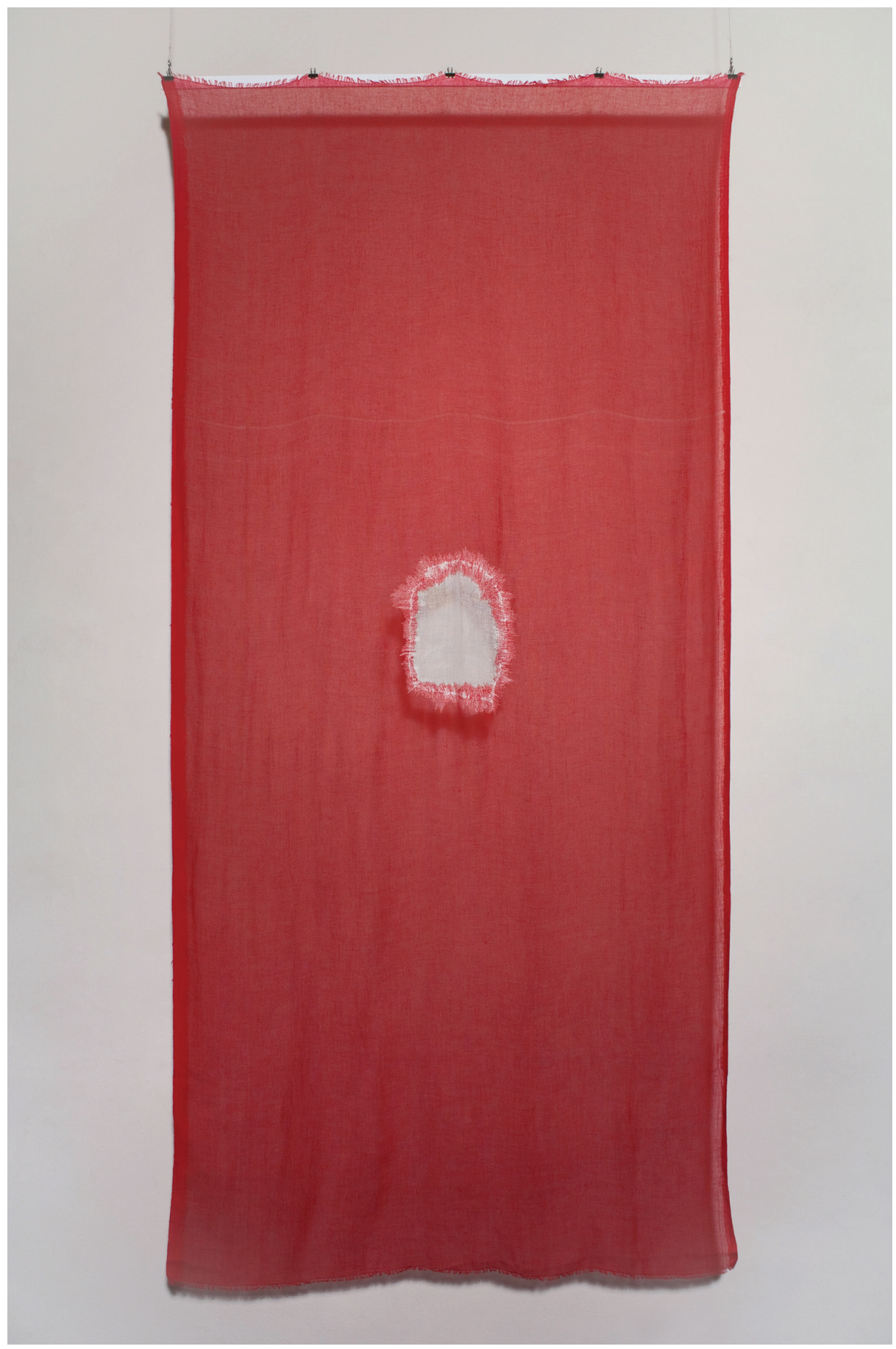

Figure 3. 
In the earlier works, breasts become layers and anatomies garments; full-size figures are constructed in opaque canvas fabric, joined together by zips and clips, so that the works can fit any space - concertinaed out, but demonstrably collapsible, so they can be toted around. When unfurled, the works resemble a disarticulated mummy - a horizontally exploded view of the body, sliced by medicine's need to know, a body peeled like an orange in one piece, the skin stretching out and springing back to demonstrate open/closed, to

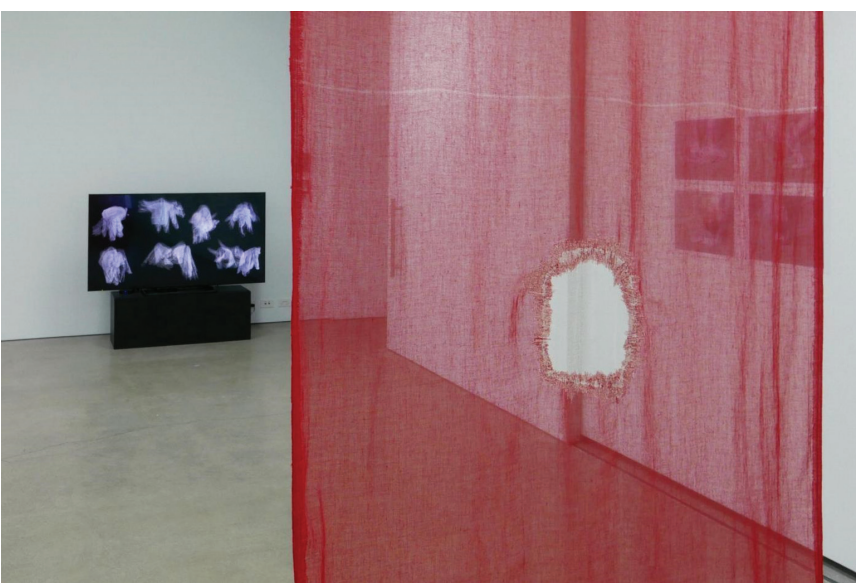

Figure 4. reveal nothing in the middle, only the bandaging forming the form.

We imagine the works going in and out like a piano accordion. We imagine our own aching spine doing the same thing. Without the flexibility of youth or a lifetime's gymnastics, we cannot imagine touching our toes. Barbara Graf's earlier works have the strange effect of making me want to be able to touch my toes. They also make me think of a medieval torture device, the rack, the painfulness of back injury as the body opens and closes at will. Canvas is used extensively in these early works and is sewn meticulously with red thread. The canvas links these works materially, if not thematically, to painting and art history. These works make me think about the ideal proportions of Leonardo's Vitruvian Man measured against not-so-ideal bodies.

Over the course of years, the focus of Graf's work has shifted from an engaged textile practice to film, photography and drawing. Examining the conventional role of observation and attempting to bypass ideas of the gaze, her extensive use of gauze as an overt materiality signals both what is hidden inside the wound and the body itself.The gauze veils, shields and hides. It is used in medicine to wipe clean and expose, to cover the wound, to protect it from infection, to heal and to conceal (in some of Graf's works the cloth gauze is dyed surgical green and red). The textile works in "Volatile Bodies" veil the body repeatedly - the body being represented becomes more opaque, not less opaque, with every iteration. These works use the language of the operating theatre as a trope; things which are not necessary to see are obscured. In the photographs (as in surgery) and the films, the body is rendered into lines which fold in and on each other. The body is also obscured by the references to the small, intricate delicacy of the fabric and the innumerable tiny, perfect stitches and folds of warp and weft of the gauze itself, almost invisible to the eye. The drawings made later carry this detail through.

We are not unfamiliar with the idea of the fragmented body. Robert Gober's wax sculptures and Cindy Sherman's mannequin photographs, for example, reveal our fascination with the abject body. In Graf's work we see this play out as an accurate - if not alarming - response to medicine's dramatic insistence on getting closer to the disease (and through imaging, to a new digital form of representation), keeping the body, and the subject, at arm's length. Yet everywhere in Graf's work the subject is apparent. Albeit partial, covered and shrouded in secrecy, it alludes to a whole female subject who is never fully present and never totally available. She, whoever she is, is tantalisingly just beyond view. A foot, some skin, the side of a face may appear; the disconcerting effect of the gauze makes you not want to look, while looking, afraid of what you might see - complicating issues of looking that feminist texts have failed to resolve, such as the commercialisation of bodies in Western, youth-obsessed advertising displays. 
In the photographic works, cloths are draped over the body to reveal a belly button, an armpit, feet; the photograph is foggy, the body shrouded in mystery, doubly and triply exposed. The artist's hand is everywhere present as it works to obliterate its own labour.The body alluded to in these works is obviously female - an aging, wrinkled and hairy, bleeding or leaking one. The fabric is wrinkled and bears the weight of the embroidered drawings - of hands which congeal to form a bloody mass of organs. Even then, each thread is accounted for, stitched back into the fabric, as there is no wrong side to these works to hide the messy ends of threads.

Drawing with the sewing machine on gauze is quite a difficult thing to master. In the cloth works, some drawing, especially of hands, are quite clunky, suggesting a latex gloved hand instead of the elegant hand of a woman - latex, the thin line of defence between safety and the spread of disease. In the exhibition, the sewing-machine drawings are seen before the photographs that in turn make their way into the animations. The animations fold into each other: a simple line, black on a white background drawing of a foot, is repeated until it covers the screen, becoming an ear; the ear turns into a hundred ears and then becomes a hand or a foot before becoming something else. The lines are continually looping back and layering one onto the next, folded over again. For the viewer, these works are clearly non-narrative; you can enter into them at any point and be mesmerised by the flip-flopping of the human form, moving from one to many, from the personal to the political.

The methodology Graf employs in every instance, through fabric, photography and film, is the fold. The fold appears as the third verb on Richard Serra's list of things to do with stuff. However, in Graf's work the particularity of the fold is constantly echoed, in its material worldliness (everything fits in a suitcase), in its unfolding and expanding in the space, and then - as it reaches towards the viewer, then beyond the viewer to extend the disciplines of textiles, sculpture, photography, drawing and film, each in its turn - folding in on itself and reflecting the limits of its own expanded field. A photograph that obscures the view, a drawing that is only a line, a sculpture in space that is flat, a textile that has a hole in it ... The limits of a particular field and its overlap with another is where the fold becomes the most consistent feature of Graf's work. This apparent interdisciplinarity stems from the translation of one medium to the next; the content and methodology remain the same in each iteration, revealing or concealing the artist's body. This body is available, yet turning way. It is not the smooth, youthful body of advertising - it is present yet veiled, measured and meticulous in its delineation, but always elusive.

In Graf's extensive creative history, one work stands out, against which all the others are measured - Cloth 4 (Figure I), a red rectangle of gauze incorporating a white circle. In this work warp and weft is sewn back on itself, creating a 20-centimetre 'hole' that is not a hole - a peephole of sorts - but the tension between warp and weft is drawn away from the hole created to the labour of the artist. "What a crazy thing to do," I found myself thinking. How simple, how amazing. Usually holes are mended, especially when the thing to be mended is considered valuable or irreplaceable (like bodies), yet here the mending has created the hole. The mending itself it almost microscopic. The threads folded over are then pulled back into the fabric. This kind of attention to detail comes from working with and knowledge of a material; a distillation of all the themes of working and the meanings of other works are threaded through this work. A whole constellation of meanings swirls around and spins out of the hole. The hole has a faint red threadt that runs away from the centre. Bloodlines, the trace of life and the opening out of the body, and pain are all represented by these thin red lines, exquisitely sewn into the fabric. The gaze through the gauze is blurry. The hole that is only partially a hole is mind-bogglingly simple, yet it invokes women's labour (to mend old and worn clothes) and the craftperson's skills and understanding of the materials used every day.You can see it from both sides, dyed and resist.

Interdisciplinarity does not exist without disciplines. In Graf's work there is a clear delineation of the trajectory of the intersections between disciplines. Graf works with an understanding of the rules, but in working with materials one also understands where the rules can be bent. Textiles and sculpture cross over, and fold into photography and film. Graf's pieces work because of her extensive understanding of and empathy with textile history, as well as her familiarity with medicine's prying gaze. Yet she breaks the conventions of most textile work and extends it in other directions because of an equally knowledgeable understanding of sculpture, of representation, the body, photography and film. 
Michele Beevors is a Principal Lecturer and the studio coordinator for sculpture and ceramics at the Dunedin School of Art. She lectures in the undergraduate programme, specialising in the history of modernist sculpture. Michele holds Masters degrees from the Canberra School of Art (Australian National University) and Columbia University (New York). Her sculptural art practice embodies a feminist perspective and issues of sustainability, particularly as it affects animals. She is involved with the Aramoana Conservation Charitable Trust. 